\title{
The Effect of Feeding Behavior on Hypothalamus in Obese Type 2 Diabetic Rats with Glucagon-like Peptide-1 Receptor Agonist Intervention
}

\author{
$\mathrm{Ke} \mathrm{Lu}^{\mathrm{a}}$ Xiaoyan Chen ${ }^{\mathrm{a}}$ Jianhua Yan ${ }^{\mathrm{b}}$ Xinchun $\mathrm{Li}^{\mathrm{c}}$ Chen Huang ${ }^{\mathrm{d}}$ \\ Qi Wanc Xuelian Deng ${ }^{\mathrm{a}}$ Qiao Zou ${ }^{\mathrm{c}}$ \\ a Department of Endocrinology, First Affiliated Hospital of Guangzhou Medical University, \\ Guangzhou, China; ${ }^{b}$ Department of Radiology, The Second Affiliated Hospital of Wenzhou \\ Medical University, Wenzhou, China; ' Department of MRI, First Affiliated Hospital of \\ Guangzhou Medical University, Guangzhou, China; ${ }^{d}$ Faculty of Health Sciences, University \\ of Macau, Macau, China
}

\section{Keywords}

Obesity - Glucagon-like peptide-1 receptor agonist - Magnetic resonance imaging · Appetite regulation · Hypothalamus

\begin{abstract}
Objective: To investigate the utility of intravoxel incoherent motion-diffusion weighted imaging (IVIM-DWI) derived parameters in hypothalamus for monitoring the effect of Exendin-4 (Ex-4) intervention on the feeding behavior in obese diabetic rats within early feeding. Methods: 21 obese and 19 non-obese rats which were treated with streptozotocin injections were initially divided into an obese diabetes group $(O D, n=10)$, a non-obese diabetes group ( $D$, $n=8)$, an obese group $(O, n=9)$ and a non-obese group $(N, n=9)$. Then, the rats in the 4 groups received subcutaneous injections of Ex-4, and feeding behavior was examined at 5, 35, 65, 95 , and $125 \mathrm{~min}$. The hypothalamic function was evaluated by IVIM-DWI. Finally, the relationship between the hypothalamic function and the amount of food intake was analyzed. $\boldsymbol{R e}$ sults: In comparison with the $\mathrm{N}$ group, the food intake significantly decreased in the $\mathrm{O}, \mathrm{OD}$, and $D$ groups in response to $E x-4$. Furthermore, a significant positive correlation was found between food intake and $D$ values at different times from 5 to 125 min after Ex-4 intervention in all 4 groups. Conclusion: A direct correlation between the change of hypothalamic function and feeding behavior was detected in OD rats with Ex-4 intervention in the early feeding period. The hypothalamic D value derived from IVIM-DWI is promising to reflect the dynamic change of hypothalamic function due to intervention.

(C) 2018 The Author(s)
\end{abstract}

Published by S. Karger GmbH, Freiburg

Jianhua Yan is co-corresponding author.

Dr. Xiaoyan Chen

Department of Endocrinology

First Affiliated Hospital of Guangzhou Medical University

510120 Guangzhou, China

gzscxy@126.com 


\section{Introduction}

Exendin-4 (Ex-4), a glucagon-like peptide-1 receptor agonist (GLP-1 RA), has already been demonstrated to play a role in weight loss and appetite suppression and considered as an effective hypothalamic drug to combat type 2 diabetes in obese patients [1,2]. It is well known that the hypothalamus is the key area of regulating feeding and energy expenditure, and its neural circuit which involved the hypothalamic arcuate nucleus (ARC) is the key structure for controlling feeding behavior [3]. Briefly, circulating hormones (leptin, ghrelin, and insulin) and nutrients (blood glucose, lipids) can directly interact with the ARC through the median eminence, a leaky of blood-brain barrier (BBB), which provides a channel for external signals to exert their influence on food intake [4]. In addition to peripheral signals, ARC could also receive CNS signals within or out of hypothalamus as it contains two distinct and functional neurons: the activated neuropeptide Y (NPY) / Agouti-related peptide (AgRP) neuron and the proopiomelanocortin (POMC) / cocaine and amphetamine-regulated transcript (CART) neuron. These neurons could release neuropeptides and project to lower neurons in the paraventricular nucleus (PVN), dorsomedial nucleus, lateral hypothalamus area and ventromedial nucleus (VMH) in the hypothalamus. After that, these nuclei further project to extrahypothalamic brain regions such as the nucleus of the solitary tract (NTS) [5]. The connections of these nuclei in and out of hypothalamus, which contact with each other through neural projections to integrate peripheral and central signals and generate a feedback response, constitute a complicated network of controlling feeding. Thus, ARC plays a crucial role in the neural circuit of feeding regulation and feeding behavior control. Noteworthy, the neural circuit for feeding regulation is not limited to neural cells. For instance, the glial cells in the brain were proved to be involved in the regulation of feeding [6-8]. Yang et al. [9] recently found that stimulation of medial hypothalamic astrocytes could directly reduce the basal-and ghrelin-evoked feeding behavior through inactivation of AgRP/NPY neurons in the ARC.

Another reason that ARC plays a major in the regulation of feeding, particularly in anorexigenic regulation, is that ARC has a great number of orexigenic/anorexigenic neurons expressing GLP-1R, though it only has a small amount of nerve fiber or nerve terminals from NTS [10]. The site of brain where GLP-1 exert its anorexigenic effect is complex; for example, GLP-1 is specifically expressed in the NTS of the brain stem, whereas GLP-1 receptors (GLP-1R) are widely distributed in the hypothalamus [11]. The mechanism by which GLP-1 reduces food intake was found to be related to the increase of CART mRNA and the decrease of NPY/ AgRP mRNA in the ARC [12]. Specifically, Scott et al. [13] demonstrated that peripheral administration of GLP-1 could suppress nutrient intake involving combined activation the GLP-1R expressed on the vagal afferents and direct GLP-1R activation via ligand penetrance through the BBB. Moreover, they suggested that GLP-1 penetrating into the brain through BBB is the main pathway for the drug to induce brain activation at earlier stage of pharmacologic action. Noteworthy, because of its capability of receiving and integrating the signals from NTS and ARC nucleus to further induce satiety effect, the PVN plays a crucial role in GLP-1 regulation of feeding $[14,15]$. The fact that GLP-1 exert its anorexigenic effect through various and complex ways may remind us to study the effect of GLP-1 on the hypothalamus using a holistic view. However, it has not been reported yet how to examine the effect of GLP-1 on hypothalamus function in the clinical setting.

Recent developments in instrument technology enables us to gain deep insights into brain functions. Thus, blood- oxygen level-dependent functional magnetic resonance imaging (BOLD-fMRI) which was initially developed to observe different areas of the brain or other organs, is currently one of the most widely used techniques to study appetite control [16]. Early studies had identified differences in hypothalamic BOLD signals between obese and lean humans after glucose uptake [17]. In recent years, many studies used this neuroimaging 
Lu et al.: The Effect of Feeding Behavior on Hypothalamus in Obese Type 2 Diabetic Rats with Glucagon-like Peptide-1 Receptor Agonist Intervention

method to study various responses of hypothalamus to food or appetite related peptide. David et al. [18] had found reduced BOLD signal intensity in hypothalamus when comparing intragastric mixed-nutrient infusion with protein infusion in rats. Furthermore, Malik et al. [19] administered ghrelin intravenously to healthy volunteers after they had a meal and observed the activation of the hypothalamic area controlling appetite.

Manganese-enhanced magnetic resonance imaging (MEMRI) is another useful tool in this field. Chaudhri et al. [20] firstly utilized MEMRI in the study on mice and showed that GLP-1 could reduce the signal of the PVN and increase that the VMH. Although the contrast in MEMRI is more directly related to neural activity and could especially be applied to small brain areas such as the hypothalamus, this approach still requires some special methods to open BBB to accumulate Manganese. Importantly, potentially toxic $\mathrm{Mn}^{2+}$ doses limit the use in the clinic [21].

Diffusion-weighted imaging MRI (DWI), is a noninvasive tool to investigate the function of the CNS by mapping neuronal activities. It can detect the transition of water diffusion preceding the vascular response and reflect early biophysical events such as cell swelling and membrane expansion of activated cells [22]. To separate signals from larger vessels and minimize the noise from capillaries, intravoxel incoherent motion (IVIM) derived parameters with bi-exponential analysis of multiple b-value DWI were proposed [23]. Lizarbe et al. [24] firstly named this technology functional DWI (fDWI) and successfully detected the change of hypothalamic signal from fasting to feeding in mice by using this technique, which could improve the spatial and temporal resolution detected with BOLD. It is worth mentioning that no drug intervention studies focused on the change of hypothalamus function by using IVIM-DWI method until now.

To our knowledge, IVIM-DWI has not been used thus far to investigate the change of hypothalamic functions in response to drug interventions. Using IVIM-DWI, we aimed to figure out whether there is a potential correlation between food intake and hypothalamus function under Ex-4 administration in obese diabetic rodents.

\section{Material and Methods}

Animals

50 6-week, specific pathogen-free (SPF), male Sprague-Dawley rats weighing $140 \pm 10$ g were purchased from the Animal Experimental Center, Guangdong Academy of Medical Sciences. All rats were housed 4 per cage in a room with an alternating 12 -hour dark and light cycle and an ambient temperature of $18-22^{\circ} \mathrm{C}$. Ten rats were fed with a chow diet ( $12 \%$ fat, $67 \%$ carbohydrate, and $21 \%$ protein), the other rats $(n=40)$ were fed with a high-fat diet ( $40 \%$ fat, $41 \%$ carbohydrate, and 19\% protein) for 8 weeks. Some rats in the second group were randomly induced to obese diabetic rats.

There was no consensus in defining obesity in rodents. We defined obesity as $\geq 20 \%$ weight gain than the average of body weight of chow diet group, as described previously [25, 26]. 21 obese and 19 non-obese rats were successfully cultivated and then divided into an obese group (O) and non-obese group (N). These groups were further divided by randomly inducing diabetes via STZ (Sigma Chemical Co. St Louis, MO, USA) to obtain obese diabetes (OD) and non-obese diabetes (D) rats (fig. 1). Rats were fasted for $12 \mathrm{~h}$ prior to STZ injection. Freshly prepared $1 \%$ STZ $(0.1 \mathrm{mmol} / \mathrm{l}$ citrate buffer, $\mathrm{pH} 4.2)$ was injected intraperitoneally in a single dose (35 mg/kg body weight). After $72 \mathrm{~h}$, rats with plasma glucose level exceeding $16.6 \mathrm{mmol} / \mathrm{l}$ were considered as diabetic. Animals that did not meet this criterion were excluded from the study. A total of 11 OD and $9 \mathrm{D}$ rats were successfully modeled; 2 rats failed. All procedures were approved by the Guangzhou Medical University of Medicine Animal Care Committee (Guangzhou, China). All experiments were performed in accordance with relevant guidelines and regulations.

Plasma Analysis

Blood samples were collected from orbital venous plexus under fasting condition. Serum was obtained by centrifugation at $1,400 \times g$ for $10 \mathrm{~min}$, and blood glucose, triglyceride (TG), cholesterol (TC), and insulin were measured according to the kit manual (BHKT Co., Beijing, China). 
Lu et al.: The Effect of Feeding Behavior on Hypothalamus in Obese Type 2 Diabetic Rats with Glucagon-like Peptide-1 Receptor Agonist Intervention

Fig. 1. Workflow of building rats group.

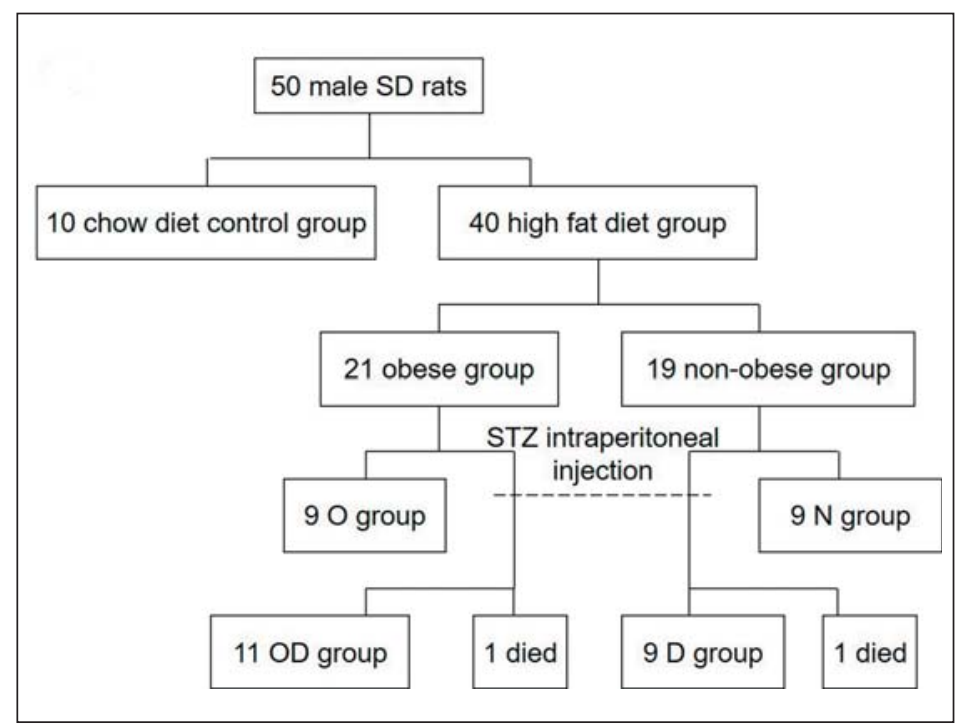

\section{Feeding}

The rats were housed individually with food deprivation but no water deprivation for $24 \mathrm{~h}$. The rats were returned to their cages immediately after subcutaneous injection of $2.5 \mu \mathrm{g} / \mathrm{kgEx}-4$ (Sigma Chemical Co. St Louis, MO, USA) at 6:00 pm, and a small can containing some standard food particles weighing $50 \mathrm{~g}$ was placed in the cage. The remaining food particles were weighed at 5, 35, 65, 95, and 125 min from the beginning of the test. The test was repeated with vehicle injection at corresponding time points to measure the basic food intake of different rats. Ex-4 can reduce the levels of orexigenic peptide such as ghrelin by nearly up to $25 \%$ in fasting rats, leading to a significant reduction of food intake in our preliminary experiment, which prompted us to choose $5 \mathrm{~min}$ as an observation time [27].

\section{Gastrostomy Surgery to Mimic Food Intake}

Each rat from 4 groups was undergone a feeding gastrostomy for MRI scanning. A $1.0 \mathrm{~mm}$ silicon rubber gastrostomy tube was placed through the greater curvature of the stomach and then tunneled subcutaneously through the midscapular region [28]. Within postoperative 5 days, rats received enteral nutrition (Fresubin HP energy, Fresenius-Kabi, Bad Homburg, Germany) containing $1.5 \mathrm{kcal} / \mathrm{ml}$ energy, with 20\% from protein, $45 \%$ from carbohydrates, and $35 \%$ from fat through the gastrostomy catheter by the continuous infusion pump. All rats were not allowed to obtain solid food but were free to drink water. One rat from the OD group and another from the D group died of infections.

\section{MRI Scans}

MRI scans were performed on a Philips Achieva 3.0T TX MR. High-fat feedstuff was grounded into a fine granular mixing with distilled water to prepare high-fat forage mixed suspension. After being anesthetized with chloralhydrate just before imaging, rats were scanned with an animal coil (Chenguang Medical Technologies Co., Shanghai, China). In the baseline scan, animals were injected subcutaneously with a dose of 2.5 $\mu \mathrm{g} / \mathrm{kg}$ Ex-4 in inner the thigh followed by a mixed suspension of $3 \mathrm{ml} \mathrm{high-fat} \mathrm{forage} \mathrm{through} \mathrm{the} \mathrm{enteral}$ nutrient canal. MRI scans were repeated at 5, 35, 65, 95, and $125 \mathrm{~min}$.

The acquisition parameters were: i) coronal T2WI /TSE: repetition time (TR) =2,200 ms, echo time (TE) = $68 \mathrm{~ms}$, slices thickness $=2 \mathrm{~mm}$, acquisition matrix $=160 \times 160$, field of view (FOV) $=60 \times 60 \times 27 \mathrm{~mm}$, number of signal averaged $(N S A)=4$. ii) IVIM DWI: using eleven b values $(0,20,40,60,80,100,200,400$, 600,800 and $1,000 \mathrm{~s} / \mathrm{mm}^{2}$ ), TR: 2,500 ms, TE: $60 \mathrm{~ms}$, slices thickness of $2 \mathrm{~mm}$, acquisition matrix: $80 \times 80$, FOV: $60 \times 60 \times 27 \mathrm{~mm}$, NSA: 3, acquisition time: $4 \mathrm{~min}, 30 \mathrm{~s}$.

\section{Image Analysis}

MR images were exported to MATLAB software (The Mathworks Inc., Natik, MA, USA) for analyses. Regions of interest (ROIs) were manually delineated by two experienced radiologists. ROIs were defined 
Lu et al.: The Effect of Feeding Behavior on Hypothalamus in Obese Type 2 Diabetic Rats with Glucagon-like Peptide-1 Receptor Agonist Intervention

Table 1. Results of weight, TG, TC and FBG in the baseline

\begin{tabular}{lllll}
\hline & $\begin{array}{l}\text { OD } \\
(\mathrm{n}=10)\end{array}$ & $\begin{array}{l}0 \\
(\mathrm{n}=9)\end{array}$ & $\begin{array}{l}\mathrm{D} \\
(\mathrm{n}=8)\end{array}$ & $\begin{array}{l}\mathrm{N} \\
(\mathrm{n}=9)\end{array}$ \\
\hline Weight, g & $522.3 \pm 31.5^{*}$ & $524.3 \pm 42.2^{*}$ & $418.0 \pm 15.1$ & $425.7 \pm 31.9$ \\
Triglyceride, mmol/l & $1.87 \pm 0.38^{*}$ & $1.34 \pm 0.37$ & $1.82 \pm 0.43^{*}$ & $1.05 \pm 0.50$ \\
Cholesterol, mmol/l & $3.45 \pm 1.14$ & $3.57 \pm 0.56$ & $3.17 \pm 0.39$ & $3.08 \pm 1.06$ \\
Fasting blood glucose, mmol/l & $11.31 \pm 4.83^{*}$ & $6.71 \pm 1.18$ & $10.51 \pm 3.96$ & $6.46 \pm 1.32$ \\
Postprandial blood glucose, mmol/l & $21.08 \pm 2.71^{*}$ & $8.10 \pm 1.32$ & $20.87 \pm 5.62^{*}$ & $7.02 \pm 0.62$ \\
Fasting insulin, mU/l & $79.36 \pm 18.72$ & $75.88 \pm 16.83$ & $60.60 \pm 18.91$ & $66.28 \pm 11.51$ \\
\hline
\end{tabular}

*Represents significant difference compared with $N$ group $(p<0.05)$.

within the hypothalamus but excluding sulcus and CSF. The bi-exponential model of attenuation of the DWI signal can be expressed by the following equation:

$$
\mathrm{S}_{\mathrm{b}} / \mathrm{S}_{0}=(1-\mathrm{f}) \exp (-\mathrm{bD})+\mathrm{f} \exp \left(-\mathrm{bD}^{*}\right)
$$

Where S represents the mean signal intensity; $b$ is the diffusion weighting factor $\left(\mathrm{s} / \mathrm{mm}^{2}\right)$; $f$ indicates the fraction of the diffusion related to microcirculation; D represents the pure molecular diffusion or slow component of diffusion, and $\mathrm{D}^{*}$ refers to perfusion-related diffusion or fast component of diffusion, which is the incoherent microcirculation within the voxel.

\section{Statistical Analyses}

Statistical analyses were performed with SPSS (version 19.0; IBM Corporation, Armonk, NY, USA). Values are presented as mean \pm standard deviation. Weight, TG, TC, fasting blood glucose (FBG), postprandial blood glucose (PBG), insulin, and the basic hypothalamic parameters of the four groups were evaluated by one-way ANOVA test. Food intake and the hypothalamic parameters of the groups after administration of Ex-4 were estimated by repeated measures of ANOVA test. Duncan multiple-range test was employed for post-hoc testing.

Correlation coefficients were obtained by Pearson's linear correlation test or Spearman rank-order test between food intake and the hypothalamic parameters according to normality examination with the ShapiroWilk test. $\mathrm{P}<0.05$ was considered as statistically significant.

\section{Results}

\section{Body Weight, TG, FBG and PBG among the Different Metabolic Rat Groups}

Based on body weight, rats were divided into an obese and a non-obese group. For each group, rats were randomly selected and induced into diabetes by STZ. As shown in table 1, weight of rats among the $\mathrm{OD}$ and $\mathrm{O}$ group were significantly higher than those among the nonobese group (around 23\% heavier). TG of the OD and D groups were higher than those of the $\mathrm{N}$ group. However, there were no significant differences for TC among these groups. Both FBG and PBG among the OD and D groups are higher than that among the N group. Fasting insulin does not show any differences among these groups.

\section{Effect of Ex-4 on Food Intake}

After Ex-4 treatment, food intake of the 4 group rats were measured at different times. As shown in figure $2 \mathrm{~A}-\mathrm{D}, \mathrm{Ex}-4$ could significantly reduce food intake of OD, D, and $\mathrm{N}$ groups compared to vehicle administration $\left(\mathrm{F}_{\mathrm{OD}}=10.545, \mathrm{P}_{\mathrm{OD}}=0.031 ; \mathrm{Fo}=3.729, \mathrm{Po}=0.126 ; \mathrm{F}_{\mathrm{D}}=\right.$ 9.429, $\left.\mathrm{P}_{\mathrm{D}}=0.032 ; \mathrm{F}_{\mathrm{N}}=55.639, \mathrm{P}_{\mathrm{N}}=0.002\right)$. As shown in figure $2 \mathrm{E}$, there was a significant difference between four metabolic rats with regard to food intake $(F=19.383, p=0.001)$. 
A

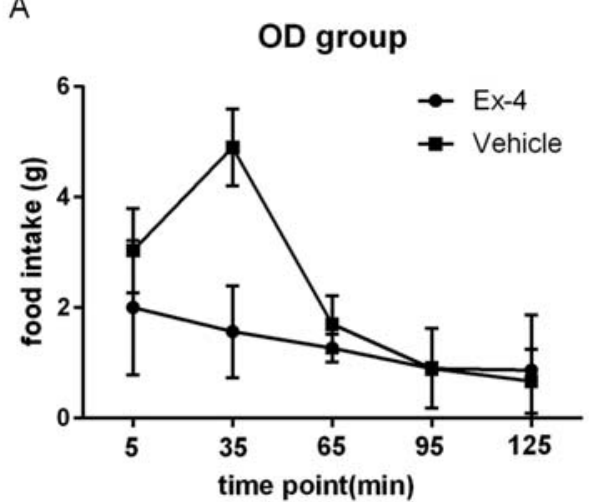

C

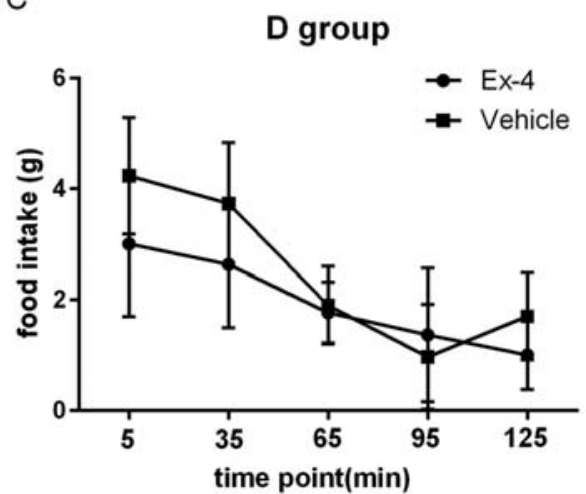

B

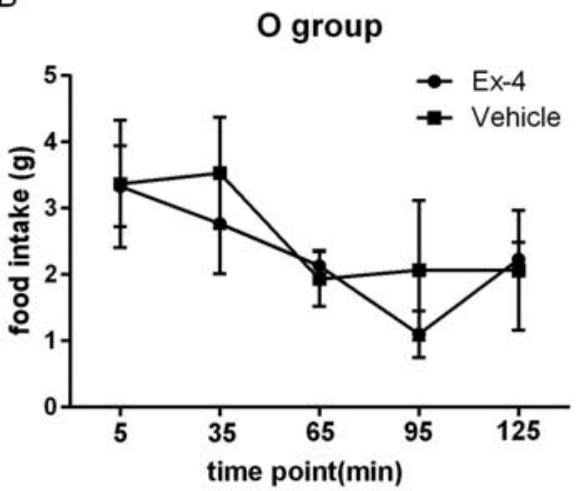

D

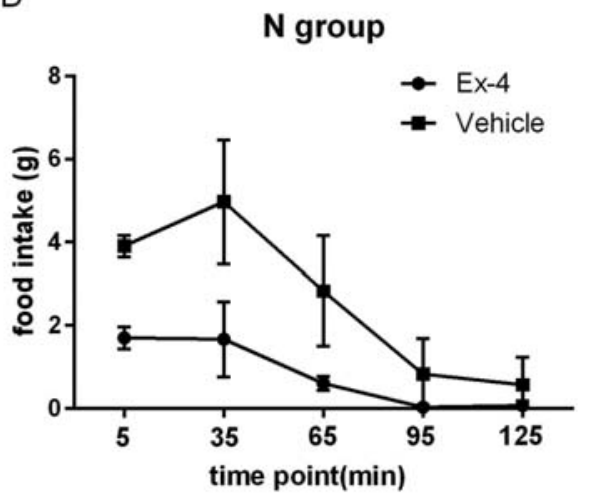

E

$\mathrm{F}$
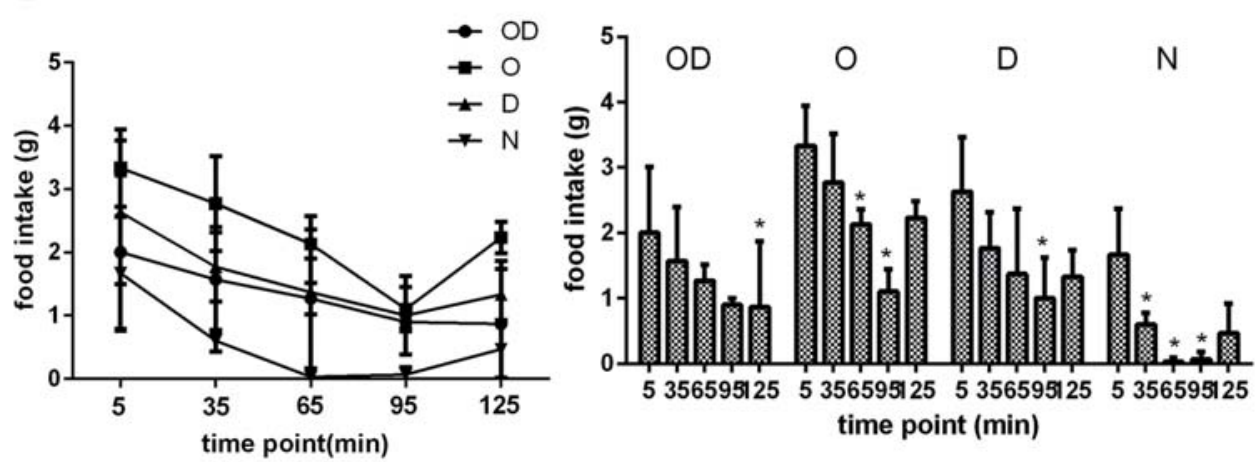

Fig. 2. Effect of peripheral Ex-4 on the suppression of food intake at different times. A-D Changes in food intake compared to vehicle intervention. E Change in food intake between groups. F Changes in food intake compared with the $5 \mathrm{~min}$ of baseline level for the same group. ${ }^{*} \mathrm{p}<0.05$. 

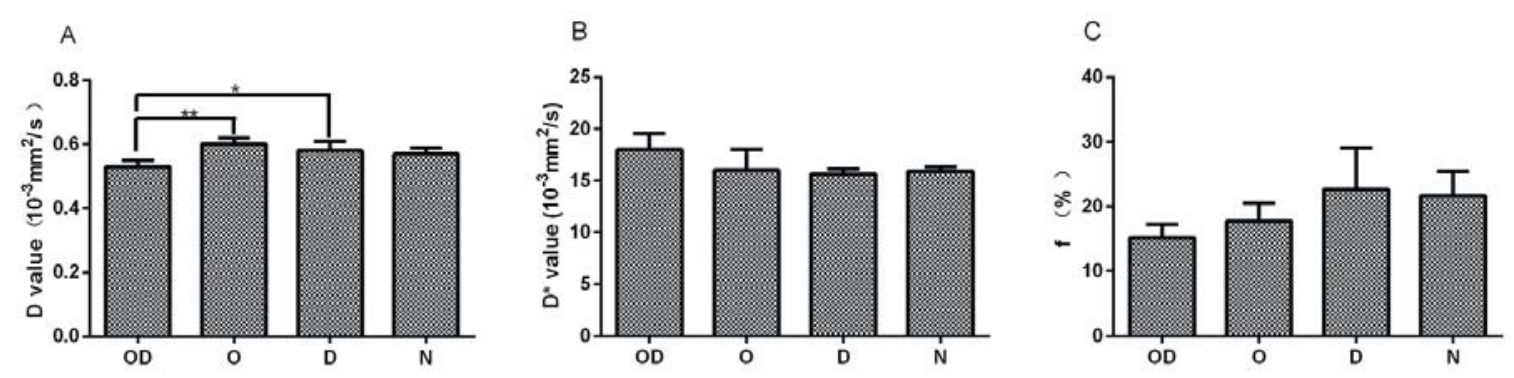

Fig. 3. The hypothalamic parameters of the four rat groups. The mean values of hypothalamic $D, D^{*}$, and $f$ of the four types of metabolic rats were shown in A-C. *p $<0.05$, ${ }^{* *} \mathrm{p}<0.01$.

Table 2. The hypothalamic D values of four metabolic rat groups before and after Ex-4 intervention

\begin{tabular}{|c|c|c|c|c|c|c|}
\hline & $0 \min$ & $5 \min$ & $35 \mathrm{~min}$ & $65 \min$ & $95 \mathrm{~min}$ & $125 \mathrm{~min}$ \\
\hline OD & $0.53 \pm 0.02$ & $0.52 \pm 0.05$ & $0.36 \pm 0.01$ & $0.28 \pm 0.01^{\#}$ & $0.25 \pm 0.01^{\#}$ & $0.29 \pm 0.01$ \\
\hline 0 & $0.60 \pm 0.02^{* *}$ & $0.52 \pm 0.02$ & $0.44 \pm 0.01$ & $0.41 \pm 0.03^{\#}$ & $0.40 \pm 0.02^{\#}$ & $0.44 \pm 0.01$ \\
\hline D & $0.58 \pm 0.03^{*}$ & $0.57 \pm 0.01$ & $0.56 \pm 0.01$ & $0.49 \pm 0.02$ & $0.45 \pm 0.01^{\#}$ & $0.50 \pm 0.02$ \\
\hline $\mathrm{N}$ & $0.57 \pm 0.02$ & $0.53 \pm 0.01$ & $0.51 \pm 0.01^{\#}$ & $0.47 \pm 0.01^{\#}$ & $0.44 \pm 0.01^{\#}$ & $0.45 \pm 0.02^{\#}$ \\
\hline
\end{tabular}

*Represents significant difference compared with OD group $(\mathrm{p}<0.05)$.

$* *$ Represents significant difference compared with OD group $(\mathrm{p}<0.01)$.

\#Represents significant difference compared with 5 min of hypothalamic D value in the same group (p < 0.05). The unit of hypothalamic D value is $10^{-3} \mathrm{~mm}^{2} / \mathrm{s}$.

Post-hoc analyses indicated that the OD $(1.32 \pm 0.81 \mathrm{~g}), \mathrm{O}(2.31 \pm 0.87 \mathrm{~g})$, and D $(1.62 \pm 0.92$ g) groups had higher food intake than the control $\mathrm{N}(0.57 \pm 0.43$ g group $(\mathrm{p}<0.05)$. The 0 group had higher food intake than the OD and D groups $(\mathrm{p}<0.05)$. Food intake did not differ between the OD and D groups ( $\mathrm{p}=0.233$ ). As shown in figure $2 \mathrm{~F}, \mathrm{Ex}-4$ significantly reduced food intake in the OD group at $125 \mathrm{~min}$, in the 0 group during 35-95 $\mathrm{min}$, in the D group at $95 \mathrm{~min}$, and in the $\mathrm{N}$ group during 35-95 min compared with the food intake at $5 \mathrm{~min}$ ( $\mathrm{p}<$ $0.05)$.

\section{IVIM Measures of the Hypothalamus at Baseline}

$D, D^{*}$, and $f$ values of hypothalamus were measured. Only the D parameters appear to show statistical significance (fig. 3A, table 2). The hypothalamic D value of OD is significantly lower than those of the $\mathrm{D}$ and $\mathrm{O}$ groups (both $\mathrm{p}<0.05$ ) but is not different from that of the $\mathrm{N}$ group $(p>0.05)$. The $D^{*}$ and $f$ values shown in figure $3 B, C$ were not statistically different among the four groups $(p>0.05)$. As shown in figure 2 , it seems that the hypothalamic $D$ value may be a more sensitive parameter to characterize the feeding behavior.

\section{Effects of Ex-4 on Hypothalamic Parameters of the Four Groups at Different Times}

Each group showed significantly different hypothalamic $\mathrm{D}$ values among groups $(\mathrm{F}=$ 43.64, $\mathrm{p}<0.01)$. D values in $\mathrm{O}\left((0.52 \pm 0.06) \times 10^{-3} \mathrm{~mm}^{2} / \mathrm{s}\right)$, OD $\left((0.44 \pm 0.08) \times 10^{-3} \mathrm{~mm}^{2} / \mathrm{s}\right)$ and $\mathrm{D}\left((0.48 \pm 0.05) \times 10^{-3} \mathrm{~mm}^{2} / \mathrm{s}\right)$ groups were significantly reduced when compared with that of the $\mathrm{N}\left((0.34 \pm 0.10) \times 10^{-3} \mathrm{~mm}^{2} / \mathrm{s}\right)$ group $(\mathrm{p}<0.05)($ fig. $4 \mathrm{~A})$. The OD group even had 
Lu et al.: The Effect of Feeding Behavior on Hypothalamus in Obese Type 2 Diabetic Rats with Glucagon-like Peptide-1 Receptor Agonist Intervention
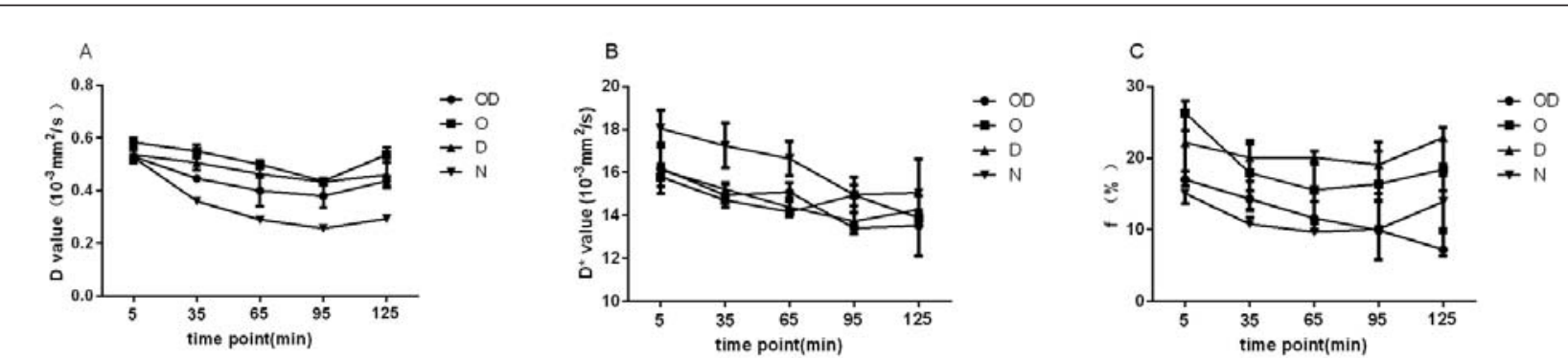

Fig. 4. The hypothalamic parameters of the four rats group at different time after peripheral Ex-4 intervention. The hypothalamic D, D*, and f values at different time were shown in A-C.

Fig. 5. Change in hypothalamic D values from the $5 \mathrm{~min}$ of baseline for each group. ${ }^{*} \mathrm{p}<0.05$.

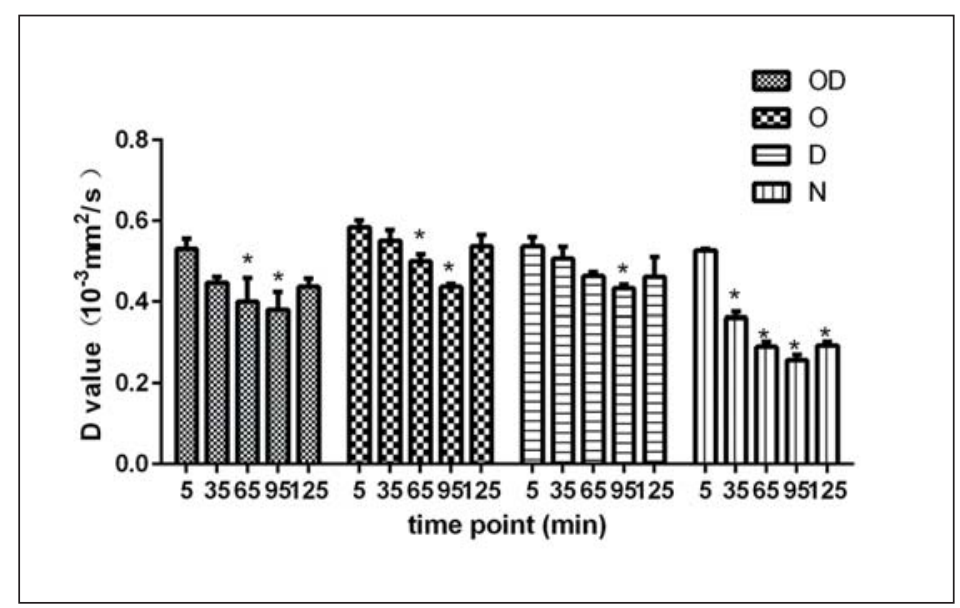

a lower hypothalamic D value than the D group that did not show assessment of food intake. The 0 group had a higher hypothalamic $D$ value than the $N$ group $(p<0.05)$. Moreover, the diagram tendency of hypothalamic D value is almost consistent with that of food intake. Consistent with figure 3 , the hypothalamic $\mathrm{D}^{*}$ and $\mathrm{f}$ values failed to show significant difference among groups and fitted with the trend of feeding behavior ( $p>0.05$ ) (fig. $4 B, C)$.

\section{Effects of Ex-4 on Hypothalamic D Value for Each Group}

Ex-4 significantly reduced hypothalamic D value in the OD group from 65 to $95 \mathrm{~min}$, in the 0 group during 65-95 $\mathrm{min}$, in the D group at $95 \mathrm{~min}$, and in the $\mathrm{N}$ group after $35 \mathrm{~min}(\mathrm{p}<$ 0.05) (fig. 5, table 2).

\section{Correlations between Changes of Food Intake and IVIM-Derived Measures after Ex-4}

\section{Administration}

Significant positive correlations between changes of food intake and hypothalamic D value after Ex-4 intervention were shown in figure 6. A significant positive correlation was observed between the food intake and hypothalamic D value: OD group, $r=0.633, p=0.00 ; 0$ group, $r=0.367, p=0.02$; $D$ group, $r=0.603, p=0.001 ; \mathrm{N}$ group, $r=0.342, p=0.022$. The hypothalamic $\mathrm{D}^{*}$ and $\mathrm{f}$ values showed no correlation with food intake at different times (fig. 7). The hypothalamic D value might be a good indicator to evaluate the feeding behavior model. 


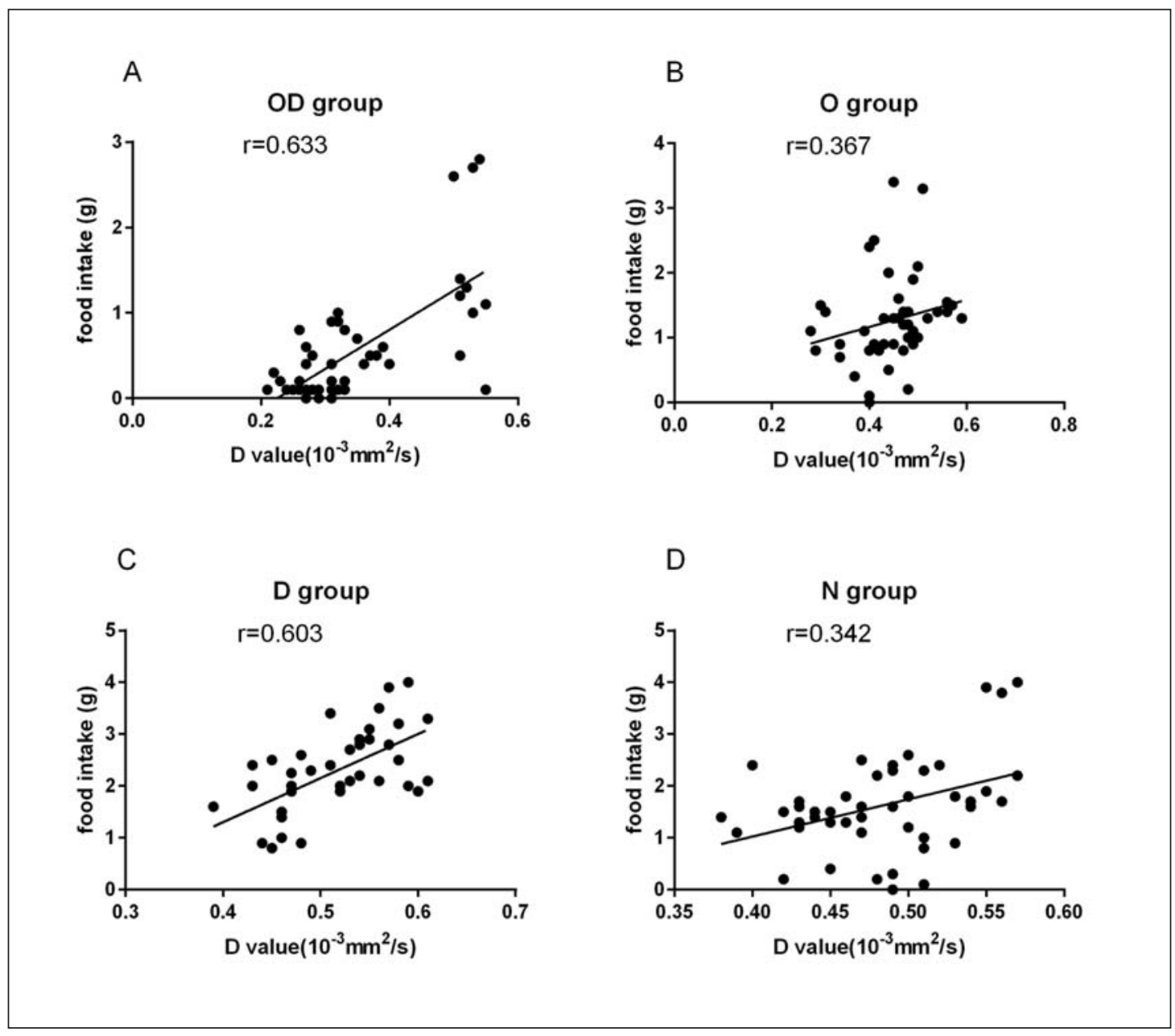

Fig. 6. Correlation between the food intake and hypothalamic $\mathrm{D}$ value for $\mathrm{OD}, \mathrm{O}, \mathrm{D}$, and $\mathrm{N}$ groups.

\section{Discussion}

Our study shows that the IVIM-DWI-derived parameters, especially D values, can be used to identify changes of hypothalamic function after Ex-4 intervention in rodents with different metabolic properties. DWI is a non-invasive method measuring random migration of water in the tissues, which has widely been used in clinical practice to detect acute cerebral ischemia (within half an hour). Our previous study [29] showed that DWI allows for objective and accurate measures of kidney function which might be helpful to for identifying diabetic nephropathy at early disease stages. IVIM-DWI technology has been applied in the diagnosis of many diseases, e.g. carcinomas, lesions or infections, but so far its application in hypothalamic feeding studies was only rarely reported [30-32]. This might be due to the tiny volume of hypothalamus the low magnetic field of which might be easily distorted. The first study using IVIM-DWI to study hypothalamic feeding was done by Lizarbe et al. [24] and revealed a significant increase of hypothalamic signal of mice in the fasting status. In agreement with the study by Lizarbe et al. [24], we also detected significant differences of the hypothalamus signal between four different metabolic groups of rats after Ex-4 intervention. In addition, both studies used $11 \mathrm{~b}$ values including 5 low b values $\left(<100 \mathrm{~s} / \mathrm{mm}^{2}\right)$ to sufficiently evaluate 
(a)

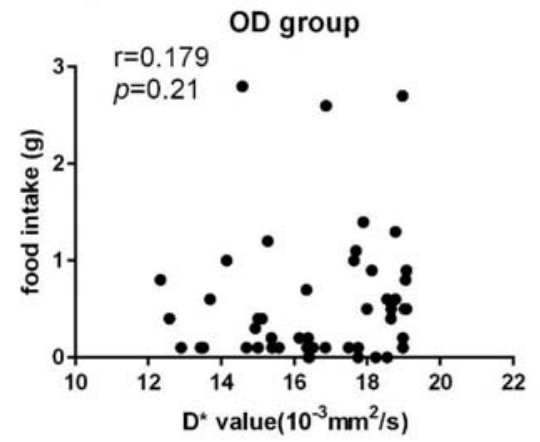

(c)

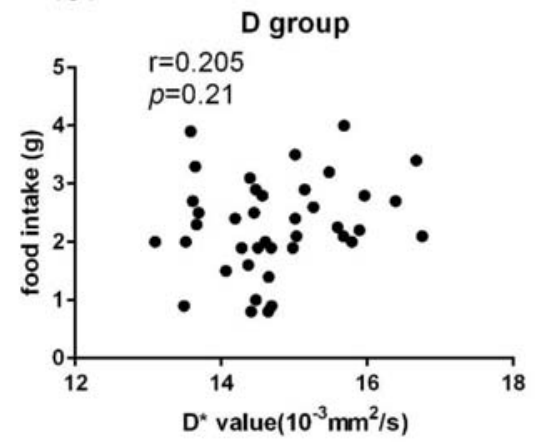

(e)

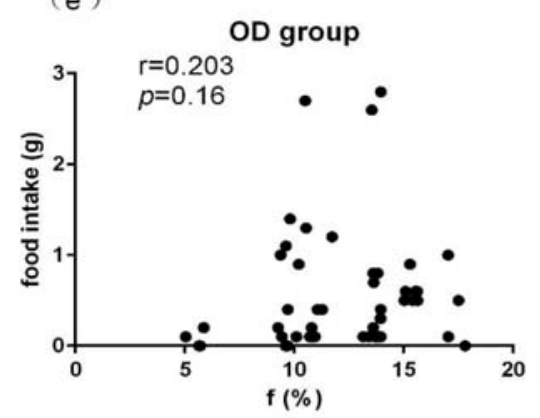

(g)

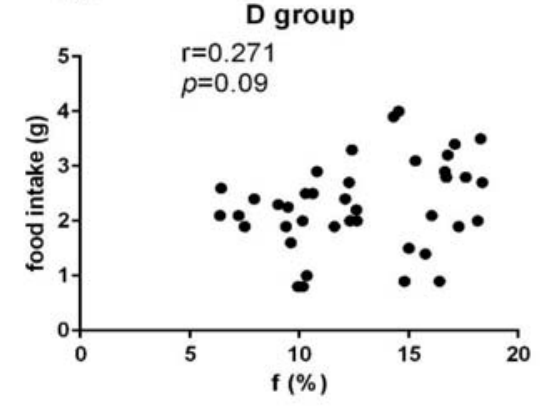

(b)

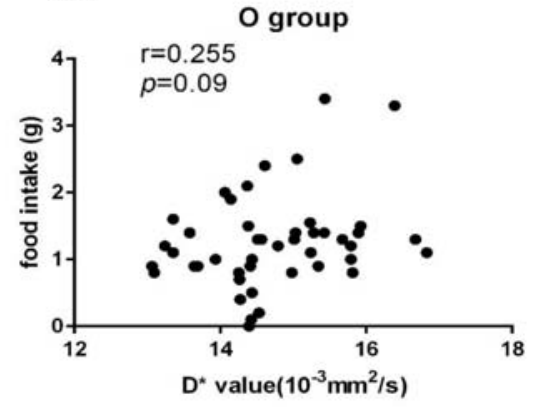

(d)

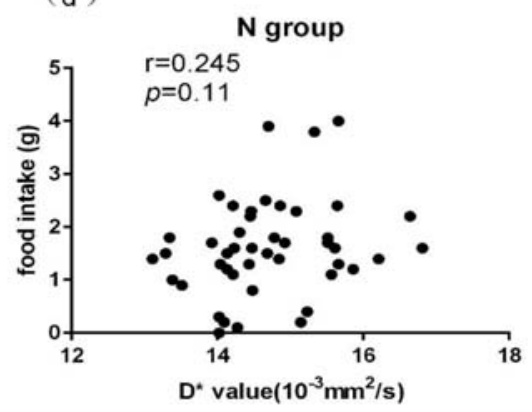

(f)

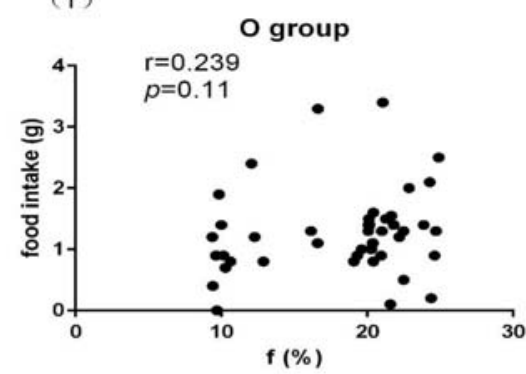

(h)

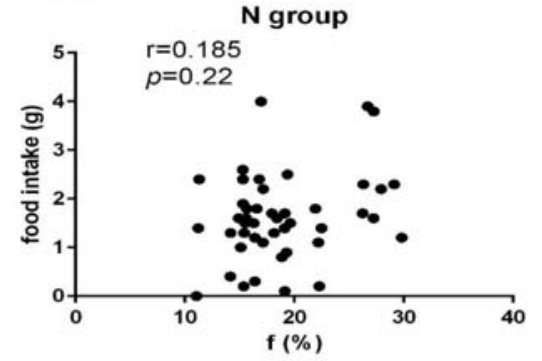

Fig. 7. Correlation between the food intake and hypothalamic $D^{*}$ and f value for $O D, O, D$, and $N$ groups. The correlation coefficient $r$ and $p$ value are indicated in each panel. The hypothalamic $D^{*}$ value (panels a-d) and f value (panels e-f) showed no correlation with food intake at different times within each group. 
Lu et al.: The Effect of Feeding Behavior on Hypothalamus in Obese Type 2 Diabetic Rats with Glucagon-like Peptide-1 Receptor Agonist Intervention

the microvascular contribution power in order to correctly discriminate the signal change among rats.

The main advantage of IVIM-DWI is that it is capable to separate the pure molecular diffusion D from the tissue perfusion intervention. For example, the D value is able to differentiate benign from malignant tissues, especially high-grade carcinomas from low-grade ones in prostate cancer or liver cell cancer $[33,34]$. Besides, the $\mathrm{D}^{*}$ value has been found to be significantly reduced in cirrhotic liver patients due to the decreased perfusion caused by liver fibrosis $[35,36]$. It was suggested that IVIM parameters are feasible to reflect the histopathologic features of different organs. In the present study, the hypothalamic D value was proven to show a good fit with food intake, suggesting that it could be applied to study hypothalamic feeding-related function. However, the perfusion-relevant parameters ( $\mathrm{f}$ and $\mathrm{D}^{*}$ value) failed to reflect the food intake behavior, suggesting that changes of hypothalamic microcirculation do not play a significant role in the control of appetite. The $D$ value, referring to the real diffusion index may reflect the volume change of astrocytes due to the osmotic swelling stimulated by feeding-related neurons [24]. Recently, Lizarbe et al. [37] investigated mice genetically deficient in leptin or NPY pathways in the hypothalamus using fDWI with 7T MRI. They not only observed significantly larger increases in the diffusion parameters SDP and $\mathrm{D}_{\text {slow }}$ in leptin-deficient mice when compared to controls, but also could not show any variations of the SDP and $D_{\text {slow }}$ parameters in NPY-deficient mice, suggesting that fDWI is an adequate measure to investigate in vivo hypothalamic pathways of appetite disorders.

At baseline, OD rats have a lower hypothalamic $D$ value than other rats indicating that $O D$ rats had a relatively lower hunger signal compared to other groups. Wellman et al. [38] used BOLD-fMRI to investigate the relationship between ghrelin (a sole orexigenic gut hormone secreted by the stomach that induced increasing food intake) and rats' behaviors and observed a stimulated signal after ghrelin administration . Moreover, Goldstone et al. [39] demonstrated that there is similar hypothalamic performance when comparing ghrelin administration after feeding and fasting status in normal subjects. These studies suggested that ghrelin has a key role in starting feeding behavior as the level of plasma ghrelin increased before feeding and decreased after feeding. The lower hypothalamic D values of OD rats might thus be explained by reduced plasma ghrelin as a result of obesity and diabetes $[40,41]$. Notably, it can be further speculated that the coexistence of obesity and type 2 diabetes may further influence the release of the hypothalamus feeding center signal.

After Ex-4 intervention, the sequential sensitivity of the hypothalamus to Ex-4 intervention in our study follows the pattern $\mathrm{O}<\mathrm{OD} \approx \mathrm{D}<\mathrm{N}$. Haiko et al. [42] found that even among people with obesity, there are different hypothalamic responses to Ex-4. By using resting-state fMRI they observed that Ex-4 responders showed significantly higher involvement of the hypothalamus than non-responders. This finding indicates that the hypothalamic response on GLP-1 could play a crucial role in food intake. In addition, Masafumi et al. [43] found that the hypothalamic inhibitory response after oral glucose ingestion was markedly attenuated and delayed in patients with obesity when compared with non-obese ones. Solrun et al. [44] demonstrated that glucose ingestion failed to decrease the hypothalamic feeding signal in obese diabetic patients. They concluded that the abnormal metabolic state of these subjects contributed to the improper response of the hypothalamus to triggers such as nutrition and many gut peptides, which may hamper the postprandial feeling of satiety in obese diabetic patients. The above mentioned studies suggested that obesityrelated factors may inhibit the response of hypothalamus to glucose intake. In the present study, the feeding inhibition demonstrated in the OD and $\mathrm{O}$ groups when compared to the $\mathrm{N}$ group may be related to the obesity-related factor influencing the response of the hypothalamus to Ex-4. In addition, the effects on feeding behavior in the OD, D and 0 groups in response to changes of the hypothalamic D value were found to be delayed when compared 
Lu et al.: The Effect of Feeding Behavior on Hypothalamus in Obese Type 2 Diabetic Rats with Glucagon-like Peptide-1 Receptor Agonist Intervention

with the $\mathrm{N}$ group. For example, the food intake in the OD group decreased at $125 \mathrm{~min}$, whereas IVIM-DWI showed that the obvious inhibition of the hypothalamic D value was at 65 and 95 min. One reason may be that patients with obesity had an abnormal high level of ghrelin which was maintained over longer time after meals so that no significant decreased food intake was observed from 0 to $95 \mathrm{~min}[45,46]$ and the food intake between meals was increased. In rodents, the inhibition signal ahead of feeding behavior may trigger a dynamic process of continuously decreasing subjective hunger and enhanced the effect of the drug.

We found a consistent correlation between food intake and the hypothalamic D value for each metabolic group after Ex-4 administration. It is supposed that intubated feeding, which bypasses oropharyngeal and esophageal exposure leading to longer gastric emptying time and reduced insulinemic responses (IR), may have more pronounced effects on appetiteregulating enzymes than oral feeding. But no significant differences between the two conditions were detected with regard to insulin, GLP-1 or ghrelin as well as with regard to satiety ratings or even food intake [47-49]. One could argue that the mixed suspension of feeding powder would have shorter time course of nutrition absorption which may influence the bioavailability of nutrition. A previous study has shown that ingestion in solid form has the same bioequivalence as the suspension or other solution form, which may imply that the delivered form of food might not always significantly influence the process of absorption related to appetite control [50].

Our study is hampered by several limitations. First, hormones such as ghrelin and leptin in the plasma were not measured. Thus it was not objectively and directly demonstrated that these obesity-related factors had an impact on hypothalamic signal and feeding behavior. Secondly, the effect of anesthetization on the hypothalamic IVIM-DWI parameters was not known. Thirdly, the coexistence of obesity and type 2 diabetes may further influence the release of the parameters in the hypothalamus feeding center at baseline. TheEx-4 injections resulted in a significant inhibition of the early feeding behavior of OD rats. Whether or not obesity-related factors such as feeding-related peptides change feeding behavior and hypothalamic function requires further investigations. Finally, a clinical 3T MR scanner is inferior to scan rat brain. However, IVIM-derived parameters can be used to identify different responses to Ex-4 in rodents differing in metabolic status. Imaging with higher than 3T MR or clinical imaging for this purpose will be investigated in the future.

\section{Conclusion}

In the present study, a direct correlation between the change of hypothalamic function and feeding behavior was detected in OD rats with Ex-4 intervention in the early feeding period. In addition, our study indicated that the hypothalamic D value derived from IVIM-DWI is a promising tool to measure the dynamic change of hypothalamic function due to intervention.

\section{Acknowledgments}

This study was supported by the Guangzhou Municipal Colleges and Universities of Scientific Research Projects (2012C008), the Science and Technology Foundation of Guangzhou City (201504282007047) and the Foundation of Science and Technology Department of Guangdong Province (2016A020215169).

\section{Disclosure Statement}

The authors declare no conflict of interest. 
Lu et al.: The Effect of Feeding Behavior on Hypothalamus in Obese Type 2 Diabetic Rats with Glucagon-like Peptide-1 Receptor Agonist Intervention

\section{References}

1 Lovshin, JA: Glucagon-like peptide-1 receptor agonists: a class update for treating type 2 diabetes. Can J Diabetes 2017;41:524-535.

2 Geloneze B, de Lima-Junior JC, Velloso LA: Glucagon-like peptide-1 receptor agonists (GLP-1RAs) in the brainadipocyte axis. Drugs 2017;77:493-503.

3 Myers MJ, DP Olson: Central nervous system control of metabolism. Nature 2012;491:357-363.

-4 Rodriguez EM, Blazquez JL, Guerra M: The design of barriers in the hypothalamus allows the median eminence and the arcuate nucleus to enjoy private milieus: the former opens to the portal blood and the latter to the cerebrospinal fluid. Peptides 2010;31:757-776.

5 Roh E, Kim MS: Brain regulation of energy metabolism. Endocrinol Metab (Seoul) 2016;31:519-524.

6 Frago LM, Chowen JA: Involvement of astrocytes in mediating the central effects of ghrelin. Int J Mol Sci 2017; 18:536.

7 Kim JG, Suyama S, Koch M, Jin S, Argente-Arizon, Argente J, Liu ZW, Zimmer MR, Jeong JK, Szigeti-Buck K, Gao Y, Garcia-Caceres C, Yi CX, Salmoso N, Vaccarino FM, Chowen J, Dietrich MO, Tschop MH, Horvath TL: Leptin signaling in astrocytes regulates hypothalamic neuronal circuits and feeding. Nat Neurosci 2014;17:908-910.

-8 Reiner DJ, Mietlicki-Baase EG, McGrath LE, Zimmer DJ, Bence KK, Sousa GL, Konanur VR, Krawczyk J, Burk DH, Kanoski SE, Hermann GE, Rogers RC, Hayes MR: Astrocytes regulate GLP-1 receptor-mediated effects on energy balance. J Neurosci 2016;36:3531-3540.

9 Yang L, Qi Y, Yang Y: Astrocytes control food intake by inhibiting AGRP neuron activity via adenosine A1 receptors. Cell Rep 2015;11:798-807.

10 Vrang N, Grove K: The brainstem preproglucagon system in a non-human primate (Macaca mulatta). Brain Res 2011;1397:28-37.

-11 Katsurada K, Maejima Y, Nakata M, Kodaira M, Suyama S, Iwasaki Y, Kario K, Yada T: Endogenous GLP-1 acts on paraventricular nucleus to suppress feeding: projection from nucleus tractus solitarius and activation of corticotropin-releasing hormone, nesfatin-1 and oxytocin neurons. Biochem Biophys Res Commun 2014;451: 276-281.

12 Seo S, Ju S, Chung H, Lee D, Park S: Acute effects of glucagon-like peptide-1 on hypothalamic neuropeptide and AMP activated kinase expression in fasted rats. Endocr J 2008;55:867-874.

13 Kanoski SE, Fortin SM, Arnold M, Grill HJ, Hayes MR: Peripheral and central GLP-1 receptor populations mediate the anorectic effects of peripherally administered GLP-1 receptor agonists, liraglutide and exendin- 4 . Endocrinology 2011;152:3103-3112.

14 Sandoval DA, Bagnol D, Woods SC, D’Alessio DA, Seeley RJ: Arcuate glucagon-like peptide 1 receptors regulate glucose homeostasis but not food intake. Diabetes 2008;57:2046-2054.

15 Baraboi ED, St-Pierre DH, Shooner J, Timofeeva E, Richard D: Brain activation following peripheral administration of the GLP-1 receptor agonist exendin-4. Am J Physiol Regul Integr Comp Physiol 2011;301:10111024.

16 Neseliler S, Han JE, Dagher A: The use of functional magnetic resonance imaging in the study of appetite and obesity; in Harris RBS (ed): Source Appetite and Food Intake: Central Control, 2nd ed. Boca Raton, CRC Press/ Taylor \& Francis, 2017, chapter 6.

17 Matsuda M, Liu Y, Mahankali S, Pu Y, Mahankali A, Wang J, DeFronzo RA, Fox PT, Gao JH: Altered hypothalamic function in response to glucose ingestion in obese humans. Diabetes 1999;48:1801-1806.

$\checkmark 18$ Min DK, Tuor UI, Koopmans HS, Chelikani PK: Changes in differential functional magnetic resonance signals in the rodent brain elicited by mixed-nutrient or protein-enriched meals. Gastroenterology 2011;141:18321841.

19 Malik S, McGlone F, Bedrossian D, Dagher A: Ghrelin modulates brain activity in areas that control appetitive behavior. Cell Metab 2008;7:400-409.

20 Chaudhri OB, Parkinson JR, Kuo YT, Druce MR, Herlihy AH, Bell JD, Dhillo WS, Stanley SA, Ghatei MA, Bloom SR: Differential hypothalamic neuronal activation following peripheral injection of GLP-1 and oxyntomodulin in mice detected by manganese-enhanced magnetic resonance imaging. Biochem Biophys Res Commun 2006; 350:298-306.

21 Silva AC: Using manganese-enhanced MRI to understand BOLD. Neuroimage 2012;62:1009-1013.

-22 Le Bihan D, Urayama S, Aso T, Hanakawa T, Fukuyama H: Direct and fast detection of neuronal activation in the human brain with diffusion MRI. Proc Natl Acad Sci U S A 2006;103:8263-8268.

23 Song AW, Woldorff MG, Gangstead S, Mangun GR, McCarthy G: Enhanced spatial localization of neuronal activation using simultaneous apparent diffusion coefficient and blood oxygenation functional magnetic resonance imaging. Neuroimage 2002;17:742-750.

-24 Lizarbe B, Benítez A, Sánchez-Montañés M, Lago-Fernández LF, Garcia-Martin ML, López-Larrubia P, Cerdán S: Imaging hypothalamic activity using diffusion weighted magnetic resonance imaging in the mouse and human brain. Neuroimage 2013;64:448-457.

-25 Novelli EL, Diniz YS, Galhardi CM, Ebaid GM, Rodrigues HG, Mani F, Fernandes AA, Cicogna AC, Novelli Filho JL: Anthropometrical parameters and markers of obesity in rats. Lab Anim 2007;41:111-119.

-26 Reidelberger R, Haver A, Chelikani PK, Apenteng B, Perriotte-Olson C, Anders K, Steenson S, Blevins JE: Effects of leptin replacement alone and with exendin- 4 on food intake and weight regain in weight-reduced dietinduced obese rats. Am J Physiol Endocrinol Metab 2012;302:1576-1585. 
Lu et al.: The Effect of Feeding Behavior on Hypothalamus in Obese Type 2 Diabetic Rats with Glucagon-like Peptide-1 Receptor Agonist Intervention

-27 Pérez-Tilve D, González-Matías L, Alvarez-Crespo M, Leiras R, Tovar S, Diéguez C, Mallo F: Exendin-4 potently decreases ghrelin levels in fasting rats. Diabetes 2007;56:143-151.

28 Kotzampassi K, Kolios G, Manousou P, Kazamias P, Paramythiotis D, Papavramidis TS, Heliadis S, Kouroumalis E, Eleftheriadis E: Oxidative stress due to anesthesia and surgical trauma: importance of early enteral nutrition. Mol Nutr Food Res 2009;53:770-779.

29 Chen X, Xiao W, Li X, He J, Huang X, Tan Y: In vivo evaluation of renal function using diffusion weighted imaging and diffusion tensor imaging in type 2 diabetics with normoalbuminuria versus microalbuminuria. Front Med 2014;8:471-476.

30 Fujima N, Yoshida D, Sakashita T, Homma A, Tsukahara A, Shimizu Y, Tha KK, Kudo K, Shirato H: Prediction of the treatment outcome using intravoxel incoherent motion and diffusional kurtosis imaging in nasal or sinonasal squamous cell carcinoma patients. Eur Radiol 2017;27:956-965.

-31 Dijkstra H, Dorrius MD, Wielema M, Pijnappel RM, Oudkerk M, Sijens PE: Quantitative DWI implemented after DCE-MRI yields increased specificity for BI-RADS 3 and 4 breast lesions. J Magn Reson Imaging 2016;44: 1642-1649.

-32 Kim JW, Lee CH, Yoo KH, Je BK, Kiefer B, Park YS, Kim KA, Park CM: Intravoxel incoherent motion magnetic resonance imaging to predict vesicoureteral reflux in children with urinary tract infection. Eur Radiol 2016; 26:1670-1677.

-33 Kuru TH, Roethke MC, Stieltjes B, Maier-Hein K, Schlemmer HP, Hadaschik BA, Fenchel M: Intravoxel incoherent motion (IVIM) diffusion imaging in prostate cancer - what does it add? J Comput Assist Tomogr 2014; 38:558-564.

-34 Woo S, Lee JM, Yoon JH, Joo I, Han JK, Choi BI: Intravoxel incoherent motion diffusion-weighted MR imaging of hepatocellular carcinoma: correlation with enhancement degree and histologic grade. Radiology 2014;270: 758-767.

35 Hayashi T, Miyati T, Takahashi J, Fukuzawa K, Sakai H, Tano M, Saitoh S: Diffusion analysis with triexponential function in liver cirrhosis. J Magn Reson Imaging 2013;38:148-153.

-36 Luciani A, Vignaud A, Cavet M, Nhieu JT, Mallat A, Ruel L, Laurent A, Deux JF, Brugieres P, Rahmouni A: Liver cirrhosis: intravoxel incoherent motion MR imaging-pilot study. Radiology 2008;249:891-899.

-37 Lizarbe B, P Lopez-Larrubia, S Cerdan: fDWI evaluation of hypothalamic appetite regulation pathways in mice genetically deficient in leptin or neuropeptide Y. Neurochem Res 2015;40:2628-2638.

-38 Wellman PJ, Clifford PS, Rodriguez JA, Hughes S, Di Francesco C, Melotto S, Tessari M, Corsi M, Bifone A, Gozzi A: Brain reinforcement system function is ghrelin dependent: studies in the rat using pharmacological fMRI and intracranial self-stimulation. Addict Biol 2012;17:908-919.

-39 Goldstone AP, Prechtl CG, Scholtz S, Miras AD, Chhina N, Durighel G, Deliran SS, Beckmann C, Ghatei MA, Ashby DR, Waldman AD, Gaylinn BD, Thorner MO, Frost GS, Bloom SR, Bell JD: Ghrelin mimics fasting to enhance human hedonic, orbitofrontal cortex, and hippocampal responses to food. Am J Clin Nutr 2014;99:1319-1330.

-40 Katsuki A, Urakawa H, Gabazza EC, Murashima S, Nakatani K, Togashi K, Yano Y, Adachi Y, Sumida Y: Circulating levels of active ghrelin is associated with abdominal adiposity, hyperinsulinemia and insulin resistance in patients with type 2 diabetes mellitus. Eur J Endocrinol 2004;151:573-577.

-41 Knudsen SH, Karstoft K, Solomon TP: Impaired postprandial fullness in type 2 diabetic subjects is rescued by acute exercise independently of total and acylated ghrelin. J Appl Physiol 2013;115:618-625.

-42 Schlögl H, Kabisch S, Horstmann A, Lohmann G, Müller K, Lepsien J, Busse-Voigt F, Kratzsch J, Pleger B, Villringer A, Stumvoll M: Exenatide-induced reduction in energy intake is associated with increase in hypothalamic connectivity. Diabetes Care 2013;36:1933-1940.

-43 Matsuda M, Liu Y, Mahankali S, Pu Y, Mahankali A, Wang J, DeFronzo RA, Fox PT, Gao JH: Altered hypothalamic function in response to glucose ingestion in obese humans. Diabetes 1999;48:1801-1806.

-44 Vidarsdottir S, Smeets PA, Eichelsheim DL, van Osch MJ, Viergever MA, Romijn JA, van der Grond J, Pijl H: Glucose ingestion fails to inhibit hypothalamic neuronal activity in patients with type 2 diabetes. Diabetes 2007;56:2547-2550.

-45 English PJ, Ghatei MA, Malik IA, Bloom SR, Wilding JPH: Food fails to suppress ghrelin levels in obese humans. J Clin Endocrinol Metab 2002;87:2984.

-46 Xu, JY, McNearney TA, Chen JDZ: Impaired postprandial releases/syntheses of ghrelin and PYY (3-36) and blunted responses to exogenous ghrelin and PYY (3-36) in a rodent model of diet-induced obesity. J Gastroenterol Hepatol 2011;26:700-705.

-47 Morey S, Shafat A, Clegg ME: Oral versus intubated feeding and the effect on glycaemic and insulinaemic responses, gastric emptying and satiety. Appetite 2016;96:598-603.

-48 Spetter MS, Mars M, Viergever MA, GraafCD, Smeets PAM: Taste matters - effects of bypassing oral stimulation on hormone and appetite responses. Physiol Behav 2014;137:9-17.

-49 Veedfald S, Plamboeck A, Deacon CF, Hartmann B, Knop FK, Vilsbøll T, Holst JJ: Cephalic phase secretion of insulin and other enteropancreatic hormones in humans. Am J Physiol Gastrointest Liver Physiol 2016;310: 43-51.

50 Harris RC, Nevill M, Harris DB, Fallowfield JL, Bogdanis GC, Wise JA: Absorption of creatine supplied as a drink, in meat or in solid form. J Sports Sci 2002;20:147-151. 